\title{
Comparative analyses of the studies of magnetic fields and cancer in electric utility workers: studies from France, Canada, and the United States
}

\author{
Leeka I Kheifets, Ethel S Gilbert, Stanley S Sussman, Pascal Guénel, Jack D Sahl,
} David A Savitz, Gilles Thériault

EMF Business Area, Environment Division, Electric Power Research Institute, Palo Alto, CA, USA L I Kheifets

NCI, Radiation, Epidemiology Branch, Rockville, MD, USA E S Gilbert

Environment Division, Electric Power Research Institute, Palo Alto, CA, USA S S Sussman

INSERM, U88, Paris, France

P Guénel

Southern California Edison Company, Rosemead, CA, USA J D Sahl

Department of Epidemiology, School of Public Health, University of North Carolina, Chapel Hill, NC, USA

D A Savitz

Department of Occupational Health, Faculty of Medicine, McGill University, Montreal, Quebec, Canada

G Thériault

Correspondence to: Dr Leeka Kheifets, Electric Power Research Institute, 3412 Hillview Avenue, Palo Alto, CA 94304-1395, USA

Accepted 16 April 1999

\begin{abstract}
Objectives-To summarise and to facilitate comparison of three major studies of electric utility workers that examined the relation between quantitative measurements of occupational exposure to magnetic fields and risk of brain cancer and leukaemia. These studies have been interpreted as providing conflicting evidence. Methods-A common analytical approach was applied to data from the five cohorts included in the three studies based on original data from four of the cohorts, and published data from one additional cohort. A nested case-control design with conditional logistic regression was used to estimate the relative risk/10 microteslayears ( $\mu \mathrm{T}$-years) for each of the contributing cohorts and for the combined data. The homogeneity of these estimates among the studies was also evaluated.

Results-Apparent inconsistencies in the findings of these studies can be explained by statistical variation. Overall, the studies suggest a small increase in risk of both brain cancer and leukaemia. Different methodological choices had little impact on the results. Based on a combined analysis of data from all five studies, the relative risk/10 $\mu$ T-years was $1.12(95 \%$ confidence interval $(95 \% \mathrm{CI}) 0.98$ to 1.28$)$ for brain cancer, and 1.09 (95\% CI 0.98 to 1.21) for leukaemia.

Conclusions-The combined estimates seem to provide the best summary measures of the data from all studies. However, fluctuations in risks among studies may reflect real differences, and the exposure measurements in different studies may not be entirely comparable.

(Occup Environ Med 1999;56:567-574)
\end{abstract}

Keywords: cancer; electromagnetic fields; epidemiological methods

Many epidemiological studies have examined the association between occupational exposures to electric and magnetic fields (EMFs) and cancer, most notably brain cancer and leukaemia. ${ }^{1}$ Some of these studies have reported positive associations with employment in "electrical occupations." These studies have often had limitations, including a broad, non-specific definition of electrical occupations, no quantitative measurements of exposures to EMFs, relatively few cases of disease, and lack of information on other workplace exposures that might act as confounders. ${ }^{23}$

More rigorous case-control and cohort studies have been conducted for workers in the electricity supply industries with a specific focus on occupations with high potential for exposure to EMFs. Of special interest are three occupational studies of electric utility workers. ${ }^{4-6}$ These studies incorporate several methodological improvements, including extensive exposure measurements, moderate to large sample sizes, and control of potential confounding by other workplace exposures. Due to their focus on electric utility employees and extensive efforts to develop quantitative individual exposure measurements, these studies afford a unique opportunity to obtain a better understanding of both exposure and cancer risks among workers in the electric utility industry. However, despite improvements in study quality, results are seemingly inconsistent, with one study finding a higher risk of leukaemia $^{6}$ and another of brain cancer, ${ }^{5}$ whereas the third is largely negative. ${ }^{4}$

To increase the collective value of these studies, we conducted a comparative reanalysis that focused on exposure to magnetic fields and included only leukaemia and brain cancer as outcomes. The objectives of this analysis were to facilitate comparison of results among studies by applying common statistical methodology; to assess whether differences in statistical methods might explain apparent inconsistencies in results; to evaluate to what extent statistical variation might explain results; and to summarise and further explore patterns of risk in cohorts. The numerous differences in how the data were collected and analysed raise the possibility that reported differences could be artifacts. By following the same analysis plan for all the data sets and by emphasising results based on quantitative measures of exposure, we tried to minimise the differences due to varying measurement and statistical approaches. Also, we provide results of a combined analysis of these studies.

\section{Materials and methods}

All studies with adequate quantitative data published at the time of initiation of this project were included in the analysis. The cohorts included in our analyses were workers at Southern California Edison (SCE), ${ }^{4}$ workers at five utilities in the southeastern United States (UNC), ${ }^{5}$ and workers in Canada and France. ${ }^{6}$ Three additional studies of utility workers have 
been published ${ }^{7-9}$; they were not included due to either lack of detailed measurement data ${ }^{7}$ or insufficient time since publication for inclusion $^{89}$; studies that were not based on utility workers ${ }^{10}$ were also excluded. Because the three cohorts in the Canada-France study (Electricite de France (EdF), Ontario Hydro $(\mathrm{OH})$, and Hydro Quebec (HQ)) were defined and followed up differently, we decided at the outset to carry out a separate analysis for each of the three cohorts rather than pool the data. The principal investigators of the $\mathrm{OH}$ study chose not to collaborate in this project; thus we had to rely only on the published data for the $\mathrm{OH}$ cohort.

DESIGN ISSUES IN COMPARATIVE ANALYSES

For the comparative analyses, several steps were taken to make the studies as comparable as possible. Firstly, to arrive at a common cohort definition, all analyses were restricted to men employed for at least 1 year at one of the utilities. Secondly, to make the two mortality studies more comparable, only the underlying causes of death were included in the comparative analysis. Thirdly, to allow for additional time for the disease to progress from diagnosis to death, in defining exposure windows (see statistical approach section) the period between exposure and identification of the case was taken to be 2 years longer for mortality than for incidence data. Fourthly, to be consistent with other studies, we converted cumulative exposure to magnetic fields, which had been estimated by the original UNC presentation based on the proportion of hours spent at work, into conventional microtesslayears ( $\mu$ T-years) of exposure. Previous analyses of the Canada-France study had also included historical corrections for changes in work practices that could have influenced past exposures. Although these corrections had negligible effects on the results, they were used in the comparative analysis as well as for the EdF and HQ cohorts. Adjustment for occupational exposures other than magnetic fields did not confound the results of the individual studies; thus no adjustment was made for them in these analyses. As measurements of electric fields were available only for the Canada-France study, they were not examined in the comparative analysis.

The original SCE analyses included occupational information on exposure assessment from death certificates when this information was missing in work histories. For comparability, subjects without occupational histories from personnel records were excluded in most of the comparative analyses. To evaluate whether this exclusion affected results, alternative analyses that included subjects with occupational information from death certificates were conducted.

STATISTICS IN COMPARATIVE ANALYSES

Although some studies presented analyses based on duration of employment in various job categories, here we emphasise analyses based on estimated cumulative exposure in $\mu$ T-years. All studies were analysed with conditional logistic regression as matched case-control studies. For the UNC study, the controls for a case included all subjects who matched the case for year of birth and race, who remained alive to the date of death of the case, and who had been employed at the same utility for at least 1 year before the death of the case.

All analyses were adjusted for socioeconomic status and matching variables. The adjustment for socioeconomic status was accomplished by including a main effect for socioeconomic status in the model, or by matching socioeconomic status.

The general model was one in which the odds ratio, or relative risk, was given by $\exp (\beta$ $\mathrm{z}$ ), where $\mathrm{z}$ is either an indicator for an exposure category or a quantitative measure of exposure. For simplicity, we will refer to our odds ratio estimates as relative risks, defined as the ratio of incidences specific for age, race, and socioeconomic status, and assumed to be constant over these variables. For $\exp (\beta) 95 \%$ confidence intervals (95\% CIs) were based on the standard error for $\beta$. With the exception of SCE, these analyses were conducted with the PECAN module of the software package EPICURE, ${ }^{11}$ and statistical tests were based on the likelihood ratio statistic. For SCE, analyses were conducted by SCE investigators with the PECAN module of the software package EGRET, ${ }^{12}$ and tests were based on the estimates divided by their asymptotic standard errors. Results of statistical tests are presented only for the quantitative index of exposure and are one tailed. For analyses based on cumulative exposure, $z$ was scaled so that $\exp (\beta)$ could be interpreted as the relative risk/10 $\mu$ T-years (roughly equivalent to working as a lineman for 5 years), a convenient metric for expressing risks. For analyses based on exposure intensity, $z$ was scaled so that the $\exp (\beta)$ could be interpreted as the relative risk/ $\mu \mathrm{T}$.

For the Canada-France and UNC studies, socioeconomic status was based on the worker's job at the start of employment with five and four categories of socioeconomic status, respectively. The socioeconomic status classification from the UNC study was adopted and applied to the SCE data. The original UNC study included an adjustment for active work, and the EdF study effectively adjusted for this variable as only the active period of employees was included.

Exposure windows included the 1-10 years before diagnosis (or 3-12 years before death), and exposure $>10$ years before diagnosis $(>12$ years before death). The windows are referred to as the $>1,1-10$, and $>10$ exposure windows, where the $>1$ window is the combination of the 1-10 and $>10$ windows. As well as cumulative exposure, analyses of average exposure intensity are presented for the $>1$ window, where exposure intensity is defined as the cumulative exposure divided by the duration of employment in the $>1$ exposure window.

Emphasis was placed on estimates and tests based on treating exposure as a continuous variable. Under the assumption that risk is a monotonically increasing function of exposure, continuous analyses provide the most sensitive 
Table 1 comparison of the design of the studies included in the comparative analysis

\begin{tabular}{|c|c|c|c|c|c|c|c|c|c|c|c|}
\hline \multirow[b]{2}{*}{$\begin{array}{l}\text { Investigator } \\
\text { (date) }\end{array}$} & \multirow[b]{2}{*}{ Utility/study } & \multicolumn{7}{|l|}{ Design } & \multicolumn{3}{|l|}{ Outcome } \\
\hline & & Type of study & Cohort size & Follow up ${ }^{\star}$ & $\begin{array}{l}\text { Inclusion and follow } \\
\text { up criteria }\end{array}$ & $\begin{array}{l}\text { Minimum } \\
\text { employment }\end{array}$ & $\begin{array}{l}\text { Exposure } \\
\text { windows }(y)\end{array}$ & $\begin{array}{l}\text { Controls } \\
\text { / case }\end{array}$ & Type & Main focus & Cases \\
\hline $\begin{array}{l}\text { Sahl et al } \\
\quad(1993)^{4}\end{array}$ & $\begin{array}{l}\text { Southern } \\
\text { California } \\
\text { Edison (SCE) }\end{array}$ & $\begin{array}{l}\text { Nested } †, \ddagger \\
\text { Case-control }\end{array}$ & 36221 & $1960-88$ & $\begin{array}{l}\text { Included females; } \\
\text { included contributing } \\
\text { causes of death in } \\
\text { case-control analyses }\end{array}$ & $1 \mathrm{y}$ & $\begin{array}{l}2-10 \\
5-10 \\
2-20 \\
5-20\end{array}$ & 10 & Mortality & $\begin{array}{l}\text { Leukaemia } \\
\text { Brain cancer } \\
\text { Lymphoma }\end{array}$ & $\begin{array}{l}44 \\
32 \\
67\end{array}$ \\
\hline \multirow[t]{3}{*}{$\begin{array}{l}\text { Thériault et } \\
\text { al }(1994)^{6}\end{array}$} & $\begin{array}{l}\text { Electricite de } \\
\text { France (EdF) }\end{array}$ & $\begin{array}{l}\text { Nested }+, \ddagger \\
\text { Case-control }\end{array}$ & 170000 & $1978-89$ & $\begin{array}{l}\text { No follow up beyond } \\
\text { retirement }\end{array}$ & $1 \mathrm{y}$ & $\begin{array}{l}0-5 \\
0-20 \\
20+\end{array}$ & 4 & Incidence & $\begin{array}{l}\text { Leukaemia } \\
\text { Brain cancer } \\
\text { Melanoma }\end{array}$ & $\begin{array}{l}71 \\
60 \\
31\end{array}$ \\
\hline & $\begin{array}{l}\text { Ontario } \\
\text { Hydro }(\mathrm{OH}) \rrbracket\end{array}$ & & 31543 & $1970-89$ & $\begin{array}{l}\text { Only pensioners for } \\
\text { first } 3 \text { ys of follow up }\end{array}$ & $1 \mathrm{y}$ & $\begin{array}{l}0-5 \\
0-20 \\
20+\end{array}$ & 4 & & $\begin{array}{l}\text { Leukaemia } \\
\text { Brain cancer } \\
\text { Melanoma }\end{array}$ & $\begin{array}{l}45 \\
24 \\
57\end{array}$ \\
\hline & $\begin{array}{l}\text { Hydro } \\
\text { Quebec (HQ) }\end{array}$ & & 21749 & $1970-89$ & & $1 \mathrm{y}$ & $\begin{array}{l}0-5 \\
0-20 \\
20+\end{array}$ & 4 & & $\begin{array}{l}\text { Leukaemia } \\
\text { Brain cancer }\end{array}$ & $\begin{array}{l}24 \\
24 \\
18\end{array}$ \\
\hline $\begin{array}{l}\text { Savitz and } \\
\text { Loomis } \\
(1995)^{5}\end{array}$ & $\begin{array}{l}5 \text { US Utilities } \\
\text { (UNC) }\end{array}$ & Cohort & 138905 & $1950-88$ & & 6 months & $\begin{array}{l}2-10 \\
10-20 \\
20+\end{array}$ & - & Mortality & $\begin{array}{l}\text { Leukaemia } \\
\text { Brain cancer }\end{array}$ & $\begin{array}{l}164 \\
151\end{array}$ \\
\hline
\end{tabular}

^Duration of follow up ranged from 12 years for the EdF cohort to close to 40 years for the UNC study.

$\dagger$ Full cohort used to evaluate job category and duration of employment, nested case-control design used to evaluate quantitative exposure measurements.

$\ddagger$ In all of the case-control studies, controls were required to be similar to the case for year of birth, race, and sex, and were required to have remained at risk to the calendar year of diagnosis (or death) of the case.

$§$ Based on the original publication.

evaluation of effects. Also, they avoid the arbitrariness of choosing particular exposure categories. The estimates of the relative risk/10 $\mu$ T-years also provide a measure of risk that is comparable across studies where the magnitudes of exposure vary substantially. Relative risks by categories defined by the same cut off points for all studies are also presented. Relative risks based on exposure distribution percentile scores of 50-75, 75-90, and $>90$ for individual studies relative to $<50$ th percentile were also calculated, and are presented graphically. Because exposure levels for the $<50$ th percentile category differ by study, these relative risks are not strictly comparable across studies. Nevertheless, they are useful in showing how the exposures and risks vary by study. We also explored the influence of several different analytical and design decisions on the study results.

Although we were not able to obtain the data for the Ontario Hydro cohort, we used published results ${ }^{13}{ }^{14}$ to obtain comparable estimates. The 1996 publication ${ }^{14}$ has the advantage that it is based on data updated to include cases missed initially, but more detailed results were available in the earlier report, ${ }^{13}$ particu- larly for leukaemia. Details on these calculations are given in footnotes to the tables. We summarised these data by providing risk estimates based on combined data from all studies. These combined estimates are based on an approach described by Whitehead and Whitehead $^{15}$ that takes into account possible heterogeneity in the findings. Combined estimates are calculated by weighting the individual estimates by their inverse variances. With this combined estimate, a $\chi^{2}$ statistic testing for heterogeneity is then calculated. If this $\chi^{2}$ statistic exceeds its degrees of freedom, a parameter $\tau^{2}$ that measures variability across studies can be estimated. The estimated $\tau^{2}$ is then used to obtain new weights and confidence limits that include this additional variability. If the $\chi^{2}$ statistic is less than its degrees of freedom there is clearly no evidence of heterogeneity, and weighting studies by their inverse variances, which is equivalent to taking $\tau^{2}=0$, is recommended.

\section{Results}

Although the studies vary with respect to structure (table 1) and details of magnetic field and confounder assessment (table 2), in critical

Table 2 Comparison of exposure assessment used by the studies included in the comparative analysis

\begin{tabular}{|c|c|c|c|c|c|c|c|c|c|c|}
\hline $\begin{array}{l}\text { Investigator } \\
\text { (date) }\end{array}$ & Utility & Sampling & Instrument * & $\begin{array}{l}\text { Occupational } \\
\text { categories }(n)\end{array}$ & $\begin{array}{l}\text { Measurements } \\
(n)\end{array}$ & $\begin{array}{l}\text { Median } \\
\text { exposure } \\
\text { ( } \mu T \text {-years) }\end{array}$ & $\begin{array}{l}\text { Historical } \\
\text { correctiont }\end{array}$ & $\begin{array}{l}\text { Control for other } \\
\text { exposures } \neq\end{array}$ & $\begin{array}{l}\text { Analyses } \\
\text { based on } \\
\text { job titles }\end{array}$ & Comments \\
\hline $\begin{array}{l}\text { Sahl et al } \\
\quad(1993)^{4}\end{array}$ & $\begin{array}{l}\text { Southern California } \\
\text { Edison (SCE) }\end{array}$ & Convenience & EMDEX & 35 & 776 & 3.5 & No & No & Yes & $\begin{array}{l}17 \%-20 \% \text { lacked } \\
\text { detailed occupational } \\
\text { information }\end{array}$ \\
\hline $\begin{array}{l}\text { Thériault } \\
\text { et al } \\
(1994)^{6}\end{array}$ & $\begin{array}{l}\text { Electricite de } \\
\text { France (EdF) } \\
\text { Ontario Hydro } \\
\text { (OH) } \\
\text { Hydro Quebec } \\
\text { (HQ) }\end{array}$ & Convenience & Positron & $\begin{array}{l}37 \\
48 \\
32\end{array}$ & $\begin{array}{l}829 \$ \\
771 \S \\
466 \$\end{array}$ & $\begin{array}{l}2.2 \\
4.9 \\
6.3\end{array}$ & Yes & $\begin{array}{l}\text { SES, IARC list } \\
\text { of potential } \\
\text { carcinogens }\end{array}$ & No & $\begin{array}{l}\text { OH study location } \\
\text { (as well as job titles) } \\
\text { was used to define } \\
\text { the occupational } \\
\text { categories }\end{array}$ \\
\hline $\begin{array}{l}\text { Savitz and } \\
\text { Loomis } \\
(1995)^{5}\end{array}$ & $\begin{array}{l}5 \text { US Utilities } \\
\text { (UNC) }\end{array}$ & Random & AMEX & 28 & 2842 & 1.1 & No & $\begin{array}{l}\text { SES, PCB, } \\
\text { solvents; } \\
\text { excluded } \\
\text { nuclear workers }\end{array}$ & Yes & \\
\hline
\end{tabular}

*AMEX is capable of measuring only time weighted average (TWA) magnetic fields; EMDEX 2 and Positron are capable of measuring both electric and magnetic fields on a continuous basis (every few seconds).

†Adjustment of the current measurements based on known changes in work practices; these adjustments lead to only minor changes in exposure or risk estimates. $\ddagger$ Except for ionising radiation, estimates of occupational exposures were based on expert judgments.

$§$ Number of workers with 5 workday measurements.

IIncluding ionising radiation, chemical agents, and sunlight; information on smoking was available only for the HQ cohort. 
Table 3 Comparison of the published results of the studies included in the comparative analysis ${ }^{*}$

\begin{tabular}{|c|c|c|c|c|c|}
\hline \multirow[b]{2}{*}{ Study } & \multirow[b]{2}{*}{ Exposuret / referent } & \multicolumn{2}{|c|}{ Leukaemia } & \multicolumn{2}{|c|}{ Brain } \\
\hline & & $R R$ & $95 \% C I$ & $R R$ & $95 \% C I$ \\
\hline \multicolumn{6}{|l|}{ Sahl et al (1993) } \\
\hline SCE & Per $25 \mu$ T-years & 1.1 & 0.8 to 1.5 & 0.8 & 0.5 to 1.4 \\
\hline Thériault et al (1994) ${ }^{6}$ & $>90 \%-<50 \%$ & 1.8 & 0.8 to 4.0 & 2.0 & 0.8 to 5.0 \\
\hline EdF & & 1.9 & 0.5 to 7.8 & - & - \\
\hline $\mathrm{OH}$ & & 3.6 & 0.9 to 14.3 & 5.5 & 0.6 to 50.6 \\
\hline HQ & & 0.5 & 0.04 to 3.8 & 1.7 & 0.3 to 9.7 \\
\hline \multicolumn{6}{|c|}{ Savitz and Loomis $(1995)^{5} \quad>90 \%-<30 \%$} \\
\hline UNC & & 1.1 & 0.6 to 2.1 & 2.3 & 1.2 to 4.6 \\
\hline
\end{tabular}

*All studies presented ORs (or RRs) for categories defined by cumulative exposure, but the definition of these categories differed. For the studies of Thériault $e t$ al, the categories were defined by the 50th, 75th, and 90th percentiles of the combined data from the three studies included. For the UNC study, the categories were defined by the 30th, 50th, 70th, and 90th percentiles for all deaths, whereas for the SCE study the results were presented for the mean, median, and 99th percentiles.

†The 90th percentile for the study of Thériault et al $=15.7 \mu \mathrm{T}$-years, and the 90th percentile for the study of Savitz and Loomis $=4.3 \mu \mathrm{T}$-work-years, based on the proportion of hours spent at work, or $19.1 \mu \mathrm{T}$-years.
BRAIN CANCER

For cumulative exposure in the $>1$ window, $\mathrm{UNC}$ and $\mathrm{OH}$ had the highest relative risks/10 $\mu$ T-years (table 4). The strongest association was found in the UNC analyses of intensity of exposure or cumulative exposure in the 1-10 window.

Table 5 shows relative risks and numbers of cases for categories defined by cumulative exposure in the $>1$ year window. The number of cases in the higher exposure categories for UNC was considerably larger than for the other studies. Some evidence of an increase in relative risks with increasing exposure categories was found in the $\mathrm{EdF}, \mathrm{UNC}$, and $\mathrm{OH}$ studies, but $95 \%$ CIs were wide, especially for the $\mathrm{EdF}$ and $\mathrm{OH}$ studies. All studies but the SCE showed increased relative risks in the $>16$ $\mu$ T-years category. Also, UNC showed a consistent increase in risk for the 1-10 year exposure window, with estimated relative risks of $1.0,1.3,1.6$, and 4.4 for categories defined by the respective cut off points $0,1,2$, and $>4$ $\mu$ T-years (data not shown). The UNC study, unlike the others, also showed a reasonably consistent increase in risk for categories of average intensity of exposure, with estimated relative risks of $1.0,1.1,1.3$, and 2.2 for categories defined by the respective cut off points $0,0.2,0.4$, and $>1.0 \mu \mathrm{T}$ (data not shown).

To allow a more direct comparison of the magnitude of risk with the magnitude of exposure, we present results based on cumulative exposure to magnetic fields ( $\mu$ T-years) percentile scores of $50-75,75-90$, and $>90$, defined within the individual studies (fig 2). These results show similar patterns to analyses based on fixed cut off points, shown in table 5. However, the trend within studies seems stronger than the overall trend for all studies. For example, the 90th percentile of cumulative exposure for SCE was almost an order of magnitude higher than EdF (46 $v 5 \mu$ T-years), with differences in the baseline categories of only 5,
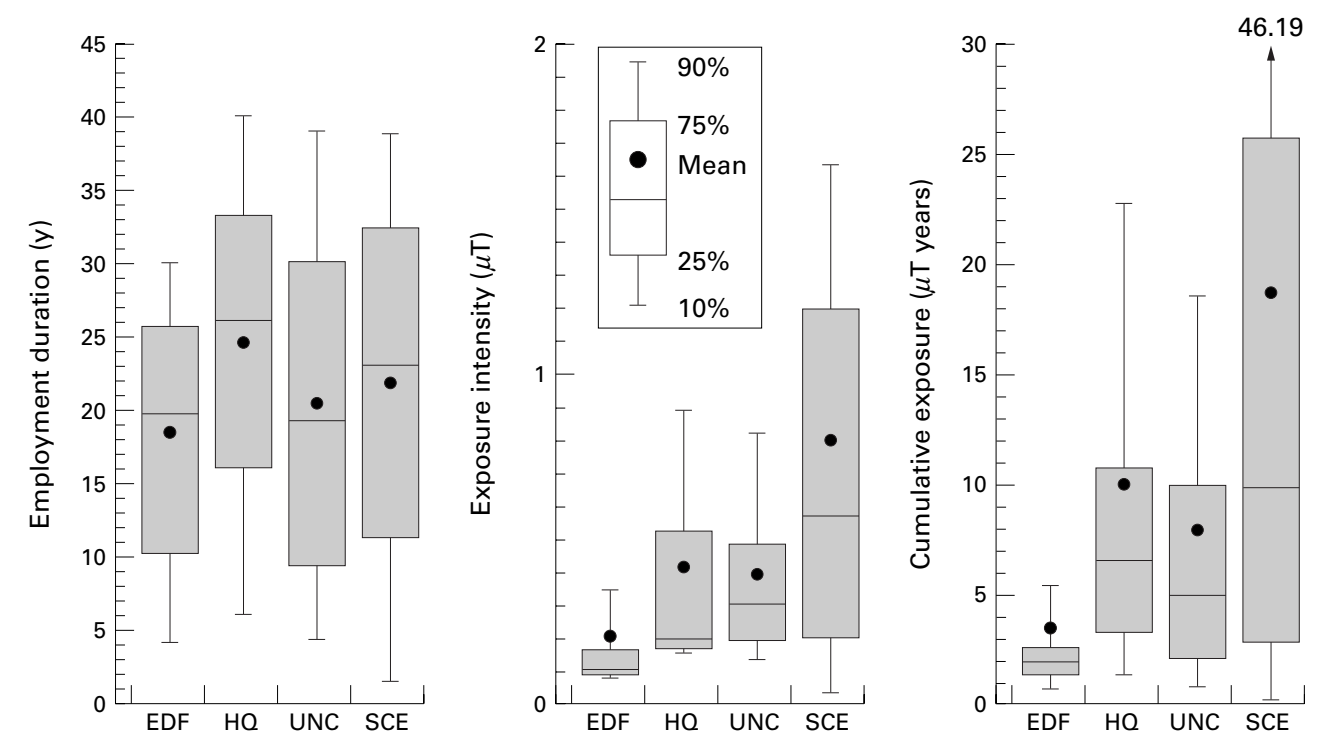

Figure 1 Distributions of duration of employment, intensity of exposure, and cumulative exposure by study. 
Table 4 Continuous analyses by exposure windows

\begin{tabular}{|c|c|c|c|c|c|c|c|c|c|c|c|c|c|c|c|}
\hline \multirow[b]{4}{*}{ Study } & \multicolumn{12}{|c|}{ Cumulative exposure ( $\mu$ T-years) } & \multirow{2}{*}{\multicolumn{3}{|c|}{$\frac{\text { Exposure intensity }(\mu T)}{>1 \text { Window }}$}} \\
\hline & \multicolumn{3}{|c|}{$>1$ Window } & \multicolumn{3}{|c|}{10 Window } & \multicolumn{3}{|c|}{$>10$ Window } & \multicolumn{3}{|c|}{$>1$ Window } & & & \\
\hline & \multicolumn{9}{|c|}{ Continuous* } & \multicolumn{3}{|c|}{ Scoret } & \multicolumn{3}{|c|}{ Continuous ${ }^{\star}$} \\
\hline & $R R$ & $95 \% C I$ & $p$ Value $\neq$ & $R R$ & $95 \% C I$ & $p$ Value $\neq$ & $R R$ & $95 \% C I$ & $p$ Value $\neq$ & $R R$ & $95 \% C I$ & $p$ Value $\neq$ & $R R$ & $95 \% C I$ & $p$ Value $\neq$ \\
\hline \multicolumn{16}{|l|}{ Brain: } \\
\hline $\mathrm{EdF}$ & 1.06 & 0.75 to 1.49 & 0.37 & 0.78 & 0.21 to 2.90 & 0.65 & 1.14 & 0.73 to 1.77 & 0.28 & 1.66 & 0.97 to 2.80 & 0.04 & 1.16 & 0.52 to 2.60 & 0.36 \\
\hline HQ & 1.05 & 0.66 to 1.52 & 0.40 & 1.14 & 0.36 to 3.60 & 0.42 & 1.06 & 0.66 to 1.71 & 0.40 & 1.08 & 0.72 to 1.62 & 0.36 & 0.94 & 0.34 to 2.60 & 0.55 \\
\hline UNC & 1.20 & 0.99 to 1.46 & 0.04 & 2.55 & 1.42 to 4.60 & 0.002 & 1.14 & 0.89 to 1.46 & 0.16 & 1.24 & 1.00 to 1.55 & 0.03 & 2.56 & 1.52 to 4.30 & $<0.001$ \\
\hline SCE & 0.99 & 0.75 to 1.32 & 0.52 & 0.90 & 0.47 to 1.72 & 0.62 & 1.01 & 0.75 to 1.37 & 0.47 & 1.04 & 0.77 to 1.41 & 0.41 & 1.28 & 0.65 to 2.50 & 0.24 \\
\hline $\mathrm{OH}(1) \mathrm{S}$ & & & & & & & & & & 1.44 & 0.89 to 2.31 & 0.07 & & & \\
\hline $\mathrm{OH}(2)$ & & & & & & & & & & 1.46 & 0.76 to 2.79 & 0.13 & & & \\
\hline \multicolumn{16}{|l|}{ Leukaemia: } \\
\hline EdF & 1.04 & 0.72 to 1.50 & 0.42 & 0.69 & 0.14 to 3.40 & 0.69 & 1.11 & 0.70 to 1.75 & 0.34 & 0.72 & 0.36 to 1.43 & 0.83 & 1.16 & 0.48 to 2.80 & 0.37 \\
\hline HQ & 0.81 & 0.46 to 1.42 & 0.78 & 0.90 & 0.22 to 3.60 & 0.56 & 0.72 & 0.34 to 1.55 & 0.82 & 0.92 & 0.57 to 1.66 & 0.61 & 0.31 & 0.05 to 1.98 & 0.92 \\
\hline UNC & 1.02 & 0.84 to 1.24 & 0.42 & 1.46 & 0.68 to 3.10 & 0.34 & 1.00 & 0.80 to 1.24 & 0.50 & 1.03 & 0.83 to 1.27 & 0.79 & 1.49 & 0.86 to 2.60 & 0.17 \\
\hline SCE & 1.12 & 0.95 to 1.33 & 0.08 & 1.03 & 0.75 to 1.42 & 0.42 & 1.14 & 0.94 to 1.39 & 0.10 & 1.13 & 0.94 to 1.37 & 0.09 & 1.39 & 0.84 to 2.30 & 0.10 \\
\hline & & & & & & & & & & 1.09 & 0.86 to 1.37 & 0.24 & & & \\
\hline $\mathrm{OH}(1)^{\star \star}$ & & & & & & & & & & & & & & & \\
\hline $\mathrm{OH}(2)$ & & & & & & & & & & 1.25 & 0.75 to 2.08 & 0.20 & & & \\
\hline
\end{tabular}

*These analyses treat exposure as a continuous variable. RRs presented are / $10 \mu \mathrm{T}$-years for cumulative exposure and / $1 \mu \mathrm{T}$ for exposure intensity

†These analyses are based on scores assigned to each of the four categories indicated in table 5 .

$¥$ One tailed $\mathrm{p}$ value for the trend test based on the continuous data.

§Based on Thériault et al, ${ }^{13}$ table 3.4, and obtained with weighted linear regression of the ORs on exposure.

"Based on Miller et al, ${ }^{14}$ table 4 , and obtained with weighted linear regression of the ORs on exposure, with the two exposure categories shown under OH(2) in table 4 .

${ }^{\star \star}$ Based on Thériault et al, ${ }^{13}$ table 3.10 , and scaled in units of $10 \mu \mathrm{T}$-years.

although the relative risk for these categories was the same $(R R=2.1)$.

Several alternative approaches were applied to these data. They included restricting analyses to subjects employed for at least 10 years, dropping the adjustment for socioeconomic status, adding stratification on active work status, including experience only for 1970 and later (as follow up did not begin until 1970 for the $\mathrm{EdF}, \mathrm{HQ}$, and $\mathrm{OH}$ cohorts), adding workers from the SCE cohort with exposure estimates based on occupational information obtained from death certificates (as in ${ }^{4}$ ), and including benign brain tumours (available only for HQ and UNC). None of these approaches modified results in any important way.

LEUKAEMIA

Overall, the studies showed little or no relation between continuous magnetic fields and leukaemia (table 4). The SCE study suggested a relation between exposure $(p=0.08)$ and leukaemia for the $>1$ exposure window, which came about because of increased risks in the two highest exposure categories of $>8 \mu \mathrm{T}$-years (table 5). The largest relative risk/10 $\mu$ T-years for the $>1$ exposure window was for $\mathrm{OH} 2$. This result was larger than that obtained from earlier data, but this might be explained by differences in the methods of calculation.

The relative risks by exposure category (table 5 and fig 3) did not indicate clear exposure-response patterns. However, for all studies except HQ, relative risks were increased in the $>16 \mu \mathrm{T}$-years category and in the $>1 \mu \mathrm{T}$ category for exposure intensity (not shown). Also, $\mathrm{OH}$ showed increased risks for all of the categories $>4 \mu$ T-years, and figure 3 shows a fairly consistent increase for SCE. The relative risks for $\mathrm{OH}$ (based on the early data) were larger than those for the other studies, and were larger than the relative risk based on the later $\mathrm{OH}$ data.

The alternative analytical approaches evaluated for risk of brain cancer were also applied to the leukaemia data. Again, these decisions

Table 5 Analyses by cumulative exposure*

\begin{tabular}{|c|c|c|c|c|c|c|c|c|c|c|c|}
\hline \multirow[b]{3}{*}{ Study } & \multicolumn{11}{|c|}{ Cut off points ( $\mu$ T-years) } \\
\hline & \multicolumn{2}{|c|}{$0-4$} & \multicolumn{3}{|c|}{$4-8$} & \multicolumn{3}{|c|}{$8-16$} & \multicolumn{3}{|c|}{$>16$} \\
\hline & $n$ & $R R$ & $n$ & $R R$ & $95 \% C I$ & $n$ & $R R$ & $95 \% C I$ & $n$ & $R R$ & $95 \% C I$ \\
\hline \multicolumn{12}{|l|}{ Brain: } \\
\hline EdF & 49 & 1.0 & 5 & 1.3 & 0.4 to 3.9 & 3 & 1.3 & 0.3 to 5.5 & 2 & 1.7 & 0.3 to 9.7 \\
\hline $\mathrm{HQ}$ & 8 & 1.0 & 8 & 2.8 & 0.6 to 12.2 & 2 & 0.5 & 0.1 to 3.2 & 6 & 1.5 & 0.3 to 6.9 \\
\hline UNC & 62 & 1.0 & 35 & 1.3 & 0.8 to 2.0 & 22 & 1.2 & 0.7 to 2.0 & 23 & 2.1 & 1.2 to 3.6 \\
\hline SCE & 8 & 1.0 & 2 & 0.4 & 0.1 to 2.3 & 3 & 0.5 & 0.1 to 2.8 & 7 & 0.6 & 0.1 to 3.0 \\
\hline $\mathrm{OH}(1) \dagger$ & 7 & 1.0 & 13 & 1.1 & 0.2 to 5.1 & & & & 4 & 5.5 & 0.6 to 51.6 \\
\hline $\mathrm{OH}(2) \ddagger$ & 7 & 1.0 & 7 & 1.3 & 0.3 to 5.4 & 10 & 2.4 & 0.5 to 10.8 & & & \\
\hline \multicolumn{12}{|l|}{ Leukaemia: } \\
\hline EdF & 62 & 1.0 & 6 & 2.1 & 0.7 to 6.1 & 1 & .5 & 0.1 to 3.8 & 3 & 1.9 & 0.5 to 7.8 \\
\hline HQ & 7 & 1.0 & 6 & 0.3 & 0.1 to 1.3 & 8 & 0.9 & 0.2 to 3.8 & 3 & 0.6 & 0.1 to 3.3 \\
\hline UNC & 69 & 1.0 & 41 & 1.1 & 0.7 to 1.8 & 26 & 1.0 & 0.6 to 1.7 & 22 & 1.4 & 0.8 to 2.4 \\
\hline SCE & 6 & 1.0 & 3 & 1.0 & 0.2 to 4.8 & 7 & 1.6 & 0.4 to 6.4 & 15 & 1.5 & 0.4 to 6.3 \\
\hline $\mathrm{OH}(1) \rrbracket$ & 9 & 1.0 & 13 & 2.6 & 0.9 to 7.3 & 17 & 6.6 & 2.0 to 22.0 & 6 & 3.6 & 0.9 to 14.3 \\
\hline $\mathrm{OH}(2) \ddagger$ & 10 & 1.0 & 16 & 1.7 & 0.6 to 4.8 & 24 & 1.6 & 0.5 to 5.1 & & & \\
\hline
\end{tabular}

$\star$ Based on $>1$ exposure window.

+Based on Theriault et al (1994), ${ }^{13}$ table 3.4, and calculated from ORs presented for the $>3.1$ and $>15.7$ category.

$\ddagger$ Based on publication of Miller $e t$ al ${ }^{14}$ (cut off points: 0 to $3.1,3.1$ to $7.1,>7.1 \mu \mathrm{T}$-years).

§Based on Thériault et al (1994), ${ }^{13}$ table 3.10 (cut off points: $0-3.1,3.1-6.9,6.9-15.7,>15.7 \mu$ T-years). 


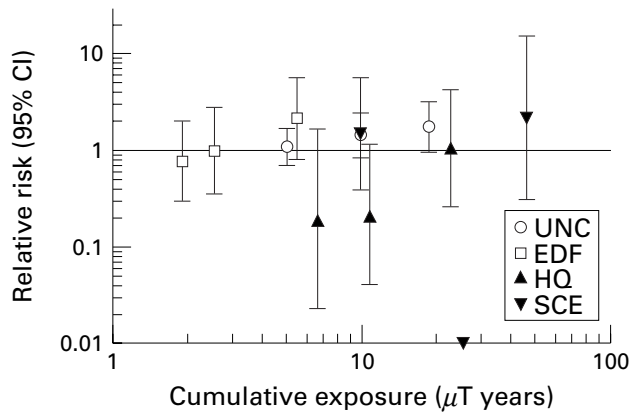

Figure 2 Brain cancer analysis of cumulative exposure based on the percentiles of the distribution. Risk shown for $50-75,75-90$, and $>90$ percentiles of distribution for each study with $<50$ as a comparison, from the $>1$ exposure window. There were no cases in the 75-90th percentile category for SCE.

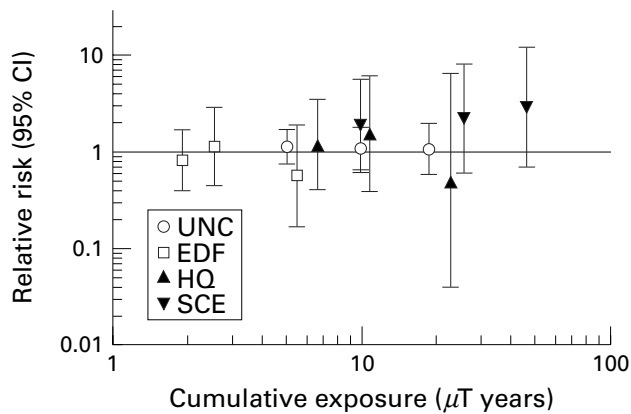

Figure 3 Leukaemia analysis of cumulative exposure based on the percentiles of the distribution. Risk shown for 50-75, 75-90, and $>90$ percentiles of distribution for each study with $<50$ as a comparison, from the $>1$ exposure window.

did not seem to have a substantial influence on the results. Separate analyses of acute myeloid leukaemia (AML) and chronic lymphocytic leukaemia (CLL) were conducted. These analyses were not very informative because of small numbers; however, they provided no indication that results for these subtypes differed from results for all leukaemias.

COMBINED ANALYSES

Table 6 shows results of analyses based on combined data. Because we could use only published $\mathrm{OH}$ data, we have shown the results both with and without them. Evidence of heterogeneity was found only in analyses by exposure category for leukaemia when the $\mathrm{OH}$ data were included. We accordingly allowed for this heterogeneity.

Whether or not the $\mathrm{OH}$ data were included, the estimated relative risks/10 $\mu$ T-years were similar for brain cancer and leukaemia - about 1.1 in both cases. Without the $\mathrm{OH}$ data, the relative risks by exposure category did not show a consistent increase with exposure, but the relative risk was highest in the $>16 \mu$ T-years category. Adding the $\mathrm{OH}$ data did not greatly modify the results for brain cancer but did increase the relative risks for leukaemia, especially in the intermediate exposure categories.

The inverse variances that were used to weight the individual estimates provide a rough measure of the relative contribution of the various studies (table 6 , footnote ${ }^{\star}$ ). The large contribution of the SCE study is perhaps especially surprising, given the few cases (table 5), and can be attributed to the large exposures in this study. However, the inverse variances (and the SCE estimates) may have been influenced by a few cases with large exposures. The relatively small contribution of the $\mathrm{OH}$ study may result in part from the fact that, unlike estimates in the other studies, this estimate was based on means of three or four exposure categories rather than on continuous data.

\section{Discussion}

Our analyses clearly show that what previously seemed to be important differences in results across studies were not a result of analytical methods but may well have resulted from chance fluctuation, and that all studies are compatible with a weak association between magnetic fields and both brain cancer and leukaemia. The wide $95 \%$ CIs show the large uncertainty in many of the estimated risks, especially those from the smaller studies with lower exposures. Formal tests for heterogeneity also support statistical variation as a possible explanation for the differences among studies. In fact, the heterogeneity tests for variability among the estimated relative risks/10 $\mu$ T-years yielded $p$ values $>0.5$ for both brain cancer and leukaemia. Nevertheless, because such tests have limited power, the possibility of differences resulting for reasons other than chance cannot be ruled out.

Table 6 Combined analyses

\begin{tabular}{|c|c|c|c|c|c|c|c|c|c|c|c|c|c|c|c|}
\hline \multirow[b]{3}{*}{ Study } & \multicolumn{15}{|c|}{ Cumulative exposure ( $\mu$ T-years) } \\
\hline & \multicolumn{4}{|c|}{ Continuous } & \multicolumn{2}{|l|}{$0-4$} & \multicolumn{3}{|c|}{$4-8$} & \multicolumn{3}{|c|}{$8-16$} & \multicolumn{3}{|c|}{$>16$} \\
\hline & $R R^{\star}$ & $95 \% C I$ & $p$ Valuet & $X^{2} \ddagger$ & $n$ & $R R$ & $n$ & $R R$ & $95 \% C I$ & $n$ & $R R$ & $95 \% C I$ & $n$ & $R R$ & $95 \% C I$ \\
\hline \multicolumn{16}{|l|}{ Brain: } \\
\hline Excluding $\mathrm{OH}$ & 1.11 & 0.97 to 1.27 & 0.07 & 1.38 & 127 & 1.0 & 50 & 1.29 & 0.89 to 1.91 & 30 & 1.06 & 0.66 to 1.69 & 38 & 1.78 & 1.11 to 2.86 \\
\hline With $\mathrm{OH}(1)$ & 1.12 & 0.98 to 1.28 & 0.05 & 2.05 & 134 & 1.0 & & & & & & & 42 & 1.87 & 1.17 to 2.98 \\
\hline With $\mathrm{OH}(2)$ & 1.13 & 0.99 to 1.29 & 0.03 & 2.45 & 134 & 1.0 & 57 & 1.33 & 0.92 to 1.93 & & & & & & \\
\hline \multicolumn{16}{|l|}{ Leukaemia: } \\
\hline Excluding $\mathrm{OH}$ & 1.09 & 0.97 to 1.23 & 0.07 & 2.74 & 144 & 1.0 & 56 & 1.07 & 0.57 to 2.01 & 42 & 1.00 & 0.65 to 1.55 & 43 & 1.35 & 0.85 to 2.14 \\
\hline With $\mathrm{OH}(1)$ & 1.09 & 0.98 to 1.21 & 0.05 & 2.74 & 153 & 1.0 & 69 & 1.26 & 0.70 to 2.26 & 59 & 1.44 & 0.64 to 3.24 & 49 & 1.48 & 0.96 to 2.30 \\
\hline With $\mathrm{OH}(2)$ & 1.10 & 0.98 to 1.23 & 0.05 & 2.99 & 154 & 1.0 & 72 & 1.18 & 0.73 to 1.90 & & & & & & \\
\hline
\end{tabular}

$\star$ RRs presented are / $10 \mu$ T-years, based on estimates from individual studies, weighted by the inverse variance. For brain cancer (adjusted so they sum to unity) they were: 0.15 for EdF, 0.13 for HQ, 0.47 for UNC, 0.22 for SCE, and 0.04 for $\mathrm{OH}$. The corresponding weights for the leukaemia analyses were: 0.08 for EdF, 0.03 for $\mathrm{HQ}, 0.29$ for UNC, 0.39 for SCE, and 0.20 for $\mathrm{OH}$.

tOne tailed $\mathrm{p}$ value for the trend test based on the continuous data.

$¥$ This statistic provides a test for heterogeneity among the studies, and is approximately distributed as a $\chi^{2}$ statistic with three degrees of freedom with OH excluded and $4 \mathrm{df}$ with $\mathrm{OH}$ included; in all six cases the $\mathrm{p}$ values associated with this test were $>0.5$. 
By pooling results we were able to obtain more statistically precise estimates of risk for the electric utility workers than were previously available. The combined risk estimates for both brain cancer and leukaemia were small, with the evidence for a positive association slightly stronger for brain cancer than for leukaemia. Although an association with brain cancer was previously reported only by the UNC study, in fact all but the SCE study showed positive gradients. The summary result suggests a small positive association (relative risk 1.12/10 $\mu \mathrm{T}$ years, $95 \%$ CI 0.98 to 1.28 ), although this support must still be regarded as tenuous. For leukaemia, only $\mathrm{OH}$ had previously reported an association. Although the EdF, HQ, and UNC studies provide little evidence of a positive trend for leukaemia, the addition of the positive estimate for SCE resulted in a weak association, with a best estimate of a relative risk of $1.09 / 10 \mu \mathrm{T}$-years of exposure (95\% CI 0.98 to 1.21). In general, by showing that estimates from the individual studies were statistically compatible and by showing overall positive associations for both brain cancer and leukaemia, this comparative analysis has at least slightly strengthened the case for an association of these diseases and exposure to magnetic fields.

The selection of studies for this analysis was based on the availability of quantitative exposure measurements and on a focus on electric utility employees. This focus was meant to enhance comparability among studies by concentrating on an industry that is considered to have a potential for high exposures, a fairly stable workforce, and common work practices which have not undergone major changes. The study comparability was further improved by eliminating or minimising differences through a common approach to data analysis. The inability to re-evaluate original $\mathrm{OH}$ data represents a limitation of this comparative effort, especially because of the relatively strong associations reported for the $\mathrm{OH}$ cohort. To minimise the impact of this limitation, we incorporated published results of the $\mathrm{OH}$ cohort whenever possible.

To facilitate comparison among studies, the relation between the cumulative exposure to magnetic fields and the risk of brain cancer and leukaemia was expressed as a relative risk/10 $\mu \mathrm{T}$-years. It should be stressed that this value must be used with caution for the purpose of risk assessment or in response to public concern, because it is based only on the data at hand and does not include other relevant scientific information that would be crucial in any risk assessment effort. Furthermore, the risk estimates should not be used to extrapolate to exposure levels higher than those in the data from which the value was derived.

Our results are compatible with the several meta-analyses that included many more diverse studies. ${ }^{2-17}$ These analyses also suggested a small increase in risk for both brain cancer and leukaemia. Three studies of utility employees not included in this re-analysis did not report an association for brain cancer $^{7-9}$ or leukaemia. ${ }^{79}$ Our analysis of leukaemia sub- types was limited by small numbers and by reliance on mortality data in two cohorts; nevertheless, we found no indication of an association with chronic lymphocytic leukaemia either in individual studies or in comparison with overall leukaemia or acute myeloid leukaemia.

Some findings for individual studies had not been reported previously. In the UNC study, the strong association of brain cancer with exposure intensity is a new finding. In the SCE study, a suggestive association was found in our analysis of leukaemia, although none was found in analyses by Sahl et al. ${ }^{4}$ In this instance, there were several important distinctions, including restricting analyses to men, to leukaemia assigned as the underlying cause of death, and to subjects with occupational histories, as well as with continuous measures of cumulative exposure. Since the $\mathrm{OH}$ study is often perceived as primarily providing evidence for an association with leukaemia, it is of interest that this study has a larger point estimate of the risk/10 $\mu$ T-years for brain cancer than did the UNC study. However, non-significantly increased risks of brain cancer in higher exposure categories were also reported previously. ${ }^{6}{ }^{18}$

Exposure assessment is perhaps the most challenging aspect of research into EMFs, and an important concern in combining data is the comparability of exposure assessment methods. Both exposure meters and sampling methods differed among the studies (table 2). It is possible, for example, that the higher exposures in the SCE cohort (fig 1) are in part due to the use of convenience sampling in estimating exposures for these subjects. Also, it has been argued that the use of data on both job category and job site in the $\mathrm{OH}$ study may have led to less misclassification of dose than in other cohorts in which only job category data were used. In fact, Miller et a ${ }^{18}$ found that omitting the use of job site data substantially lessened the evidence for a dose-response relation in the $\mathrm{OH}$ study. In our study, we found no evidence of heterogeneity among studies in the estimated risks/10 $\mu$ T-years, but the possibility of differences in methods of measuring exposure affecting the results remains a consideration.

Miller $e t a l^{18}$ found evidence that exposure to electric fields may have been a stronger risk factor for leukaemia than exposure to magnetic fields in the $\mathrm{OH}$ cohort. Also, a study of exposure to electric fields in the EdF cohort found an association with risk of brain cancer (but not leukaemia), ${ }^{19}$ although earlier analyses based on exposure to magnetic fields had not identified such a correlation. ${ }^{6}$ Because quantitative measurements of electric fields were not available for all of the other cohorts, we were unable to examine this issue.

Due to inherent limitations in the data, we were unable to adequately evaluate several factors that might have led to differences in results. These include study of cancer incidence $v$ mortality, differences in the social and demographic composition of the cohorts, differences in other occupational exposures 
(including ionising radiation and electric fields), and differences in the range and level of exposures.

Despite the substantial methodological differences in the original studies, we were able to achieve a level of comparability that allowed a direct and informative comparison of study results. Generalising results from the different studies in parallel format has made it easier to compare them and to examine the relative contributions of individual studies, both in terms of numbers of cases and magnitudes of the exposures. Analysing the data from all studies in a comparable way has shown that apparent differences among studies are unlikely to be due to differences in the statistical approaches taken by various investigators. These differences are less striking and less statistically precise than they had seemed in the original publications. Exploration of the impact of different methodological choices has indicated that results are generally insensitive to these choices. Nevertheless, we cannot exclude the possibility that the fluctuations in risks among studies may reflect real differences, including differences in measuring exposure.

We thank Drs Beniamin Armstrong, William Dab, Marciele Goldberg, Michael Kelsh, and Michel Plante, as well as Jeffrey Cochiolo, who has contributed to the project from the very beginning. We also thank Drs Norman Breslow and Denis
Hemon for their review of the manuscript. We acknowledge and thank EPRI and EdF for financial support of the project.

1 Doll R. Weak associations in epidemiology. Radiological Protection Bulletin 1997;192:10-15.

2 Kheifets LI, Afifi AA, Buffler PA, et al. Occupational electric Kheifets LI, Afifi AA, Buffler PA, et al. Occupational electric and magnetic field exposure and brain cancer:

3 Kheifets LI, Afifi AA, Buffler PA, et al. Occupational electric and magnetic field exposure and leukemia: a meta-analysis. 7 Occup Environ Med 1997;39:1074-91.

4 Sahl JD, Kelsh MA, Greenland S. Cohort and nested case-control studies of hematopoietic cancers and brain cancer among electric utility workers. Epidemiology 1993;4:104 14
5 Savitz DA, Loomis DP. Magnetic field exposure in relation to leukemia and brain cancer mortality among electric utility workers. Am f Epidemiol 1995;141:123-34.

6 Thériault G, Goldberg M, Miller AB, et al. Cancer risks associated with occupational exposure to magnetic fields among electric utility workers in Ontario and Quebec, Canada, and France: 1970-89. Am f Epidemiol 1994a;139: $550-72$.

7 Tynes T, Reitan JB, Andersen A. Incidence of cancer among workers in Norwegian hydroelectric power companies. Scand $\mathcal{f}$ Work Environ Health 1994;20:339-44.

8 Harrington JM, McBride DI, Sorahan T, et al. Occupational exposure to magnetic fields in relation to mortality from brain cancer among electricity generation and transmission workers. Occup Environ Med 1997;54:7-13.

9 Johansen C, Olsen JH. Risk of cancer among Danish utility workers: a nationwide cohort study. $A m \mathcal{F}$ Epidemiol 1998; 147:548-55.

10 Floderus B, Persson T, Stenlund C, et al. Occupational exposure to electromagnetic fields in relation to leukemia and brain tumors: a case-control study in Sweden. Cancer Causes Control 1993;4:465-76.

11 Preston DL, Lubin JH, Pierce DA. EPICURE user's guide. Seattle, WA: HiroSoft, 1991.

12 Statistics and Epidemiology Research Corporation. EGRET reference manual. Seattle, WA: Statistics and Epidemiology Research Corporation, 1985.

13 Thériault G, Goldberg M, Miller AB, et al. Joint Electricite de France - Hydro Quebec - Ontario Hydro epidemiological study on the long term effects of exposure to 50 and $60 \mathrm{~Hz}$ electric and magnetic fields. Montreal, Canada: Electricite de France, Hydro-Quebec, Ontario Hydro joint report, 1994.

14 Miller AB, To T, Agnew DA, et al. Leukemia following occupational exposure to $60-\mathrm{Hz}$ electric and magnetic fields among Ontario electric utility workers. $A m$ f Epidemiol 1996;144:150-60.

15 Whitehead A, Whitehead J. A general parametric approach to the meta-analysis of randomized clinical trials. Stat Med 1991;10:1665-77.

16 Thériault GP. Health effects of electromagnetic radiation on workers: epidemiologic studies. In: Bierbaum PG, Peters JM. Proceedings of the Scientific workshop on Health Effects of Electroagnetic Fields on Work. Cincinnati: National Institute for occupational Safety and Health, 1991. (DHHs for occupational Safety a

17 Savitz DA, Ahlbom A. Epidemiologic evidence on cancer in relation to residential and occupational exposures. In: Carpenter DO, Ayrapetyan S, eds. Biologic effects of electronic and magnetic fields: benefited and harmful effects. San Diego, DA: Academic Press, 1994:233-61.

18 Bracken TD, Rankin RF. The EMDEX project residential study. Palo Alto, CA, USA: Electric Power Research Institute, 1994. (Report TR-104325.)

19 Guénel P, Nicolau J, Imbernon E, et al. Exposure to $50-\mathrm{Hz}$ electric field and incidence of leukemia, brain tumors, and other cancers among French electric utility workers. $A m \mathcal{F}$ Epidemiol 1996;144:1107-21. 